\title{
Bir Popüler Kültür Ögesi Olarak Arabesk Müziğin Çevreden Merkeze Yolculuğu
}

\author{
Onur TAYDAŞ* \\ Hale SERT ${ }^{* *}$
}

\section{ÖZ}

Türkiye'nin modernleşme serüvenine kültürel bir cevap olarak ortaya çıkışının ardından uzun süre görmezden gelinen ya da yozlaşmanın ve yabancılaşmanın müziği olarak ötelenen arabesk, elitist ve dışlayıcı tavırlar kadar resmi yasaklama ve ambargoların da nesnesi olmuştur. Ancak yaslandığı toplumsal dinamiklerin de yardımıyla kitlesel bir yayılma gösteren arabesk olgusu, giderek șehrin kültürel kodlarına eklemlenmiș; dahası bu kodları bozup yeniden üreterek baskın bir popüler kültür ögesi haline evrilmiștir. Arabeske yönelik dışlayıcı yaklaşımların temel teorik zeminini Muhafazakâr-elitist ekol ile Frankfurt Okulu geleneğine dayandırmak mümkündür. Fakat uzlaşması çok da mümkün görünmeyen bu iki geleneği popüler kültür karșıtlığında bulușturan seçkinci yaklaşımlar, Türkiye'de arabesk olgusuna dair sağlıklı çözümlemeler yapabilmeyi imkânsız kılan bir entelektüel vasat doğurmuştur. Bu vasatı kırmak üzere İngiliz Kültürel Çalışmalar geleneğinin izini takip eden bazı aydınlar, bu geleneğin popüler kültüre atfettĭği olumlu çağrışımları arabeski anlamak ve onu dönüştürmek üzere geliştirdikleri çalışmalara taşımışlardır. Bu çalışmada, modernleșme ile gelenek arasındaki gerilimli birlikteliğin ve Türkiye'nin kendine has modernleșme serencamının çeşitli kültürel tezahürlerinden biri olan "arabesk" olgusuna dair çeşitli yaklaşımlar, bahsi geçen kuramsal farklılıklar etrafinda ele alınmıştır. 1960'larla başlayan arabesk furyasının dönemsel dönüşümlerine değinilmiş, arabesk müziğin periferiden merkeze doğru seyreden yolculuğu sırasında, sahip olduğu organik niteliklerden ve taşıdığı muhalif anlamlardan soyunarak tamamladığı öyküsü üzerinde durulmuş̧tur.

Anahtar Kelimeler: Arabesk, Modernleşme, Popüler Kültür, Kültürel Çalışmalar, Hegemonya, Frankfurt Okulu.

\section{The Journey of Arabesque Music as A Popular Cultural Element From The Periphery to the Center}

\begin{abstract}
Being ignored or postponed as the music of corruption and alienation after a long time its emerge as a cultural response to Turkey's modernization adventure, arabesque has been the object of official prohibitions and embargoes as well as elitist and exclusionary attitudes. However, the phenomenon of arabesque, which spread massively with the help of the social dynamics on which it rests, gradually joined the cultural codes of the city and it has evolved into a dominant popular culture item by breaking and reproducing these codes. It is possible to base the basic theoretical basis of the exclusionary approaches to Arabesk on the Conservative-elitist school and the Frankfurt School tradition. But elitist approaches that bring these two uncompromising traditions together in the anti-popular culture, it has given birth to an intellectual medium that makes it impossible to make healthy solutions regarding the arabesque phenomenon in Turkey. Some intellectuals, following the traces of the British Cultural Studies tradition in order to break this mediocrity, have carried the positive connotations of the tradition into the works they developed to understand and transform arabesque.In this study, 'arabesque' as the tense coexistence between tradition and modernity and as one of the Turkey's various cultural manifestations; various approaches are discussed around the theoretical differences mentioned. In the study, the transformations that started in the 1960s were mentioned, and the story that it completed with the organic qualities it had in its journey from the periphery to the center and the opposing meanings it carried were emphasized.
\end{abstract}

Keywords: Arabesque, Modernization, Popular Culture, Cultural Studies, Hegemony, Frankfurt School.

\section{Giriş}

En ilkel toplumlardan günümüze kadar müzik, hem son derece bireysel hem de bir o kadar kolektif bir dışavurum aracı olarak insan yaşamının her alanına sirayet eden sanatsal etkinliğin en merkezi unsurlarından biri olmuştur. Dinsel ayinlerden çocuk oyunlarına, askeri ritüellerden sıradan eğlencelere kadar pek çok etkinliğin müzikal bir forma bürünerek toplumsal yapiya eklemlendiği bilinmektedir. Ancak bütün bu kuşatıcllı̆ına rağmen müzik, bir yönüyle hep bilinemez ve açılanamaz bir fenomen olarak kalmakta; bütün kadim sanatlar gibi o da son derece kişisel, sübjektif ve gizemli bir kaynaktan beslenmesi dolayısıyla tanımlann, kuramların ve kavramların sınırları ile tespit edilmeye direnmektedir. Üstelik müzik,

\footnotetext{
* Dr. Öğr. Üyesi., Sivas Cumhuriyet Üniversitesi, onurtaydas@hotmail.com

** Hale Sert, hale.sert@hotmail.com

Makalenin Gönderim Tarihi: 22.11.2020; Makalenin Kabul Tarihi: 01.01.2021
} 
diğer sanatlardan farklı olarak, ne gözün uzamı ile ne de mekânsal ya da sözel/dilsel bağımllıklarla sınırlandırılabilir. Bunlara ihtiyaç duymayan bir üst dil olarak müzik bir zaman sanatıdır ve bu durum onu diğer sanatların üzerine yükseltmekle birlikte ona daha da mistik ve muğlak bir karakter kazandırmaktadır. Ancak sanatların en soyutu olan "müzik, toplumla etkileşip bütünleşen sanatlarn da başında gelmektedir" (Odabaş1, 2006, s. 250).

Ünlü Rus müzisyen Stravinsky, temel doğal sesleri müziğin hammaddesi olarak kabul etmekle birlikte müziğin maddi dünyanın sınırlarını aşan karakterine atıfta bulunur. Stravinsky'e (2000, s. 23-24) göre temel "tonal ögeler ancak düzenlenmeleri sayesinde müziğe dönüsür ve böyle bir düzenleme bilinçli bir insan edimini varsayar"; ancak yine Stravinsky'e göre bu insan ediminin ve "her türlü yaratımın kaynağında, bu dünyanm nimetlerine yönelik olmayan bir istah kesfedilebilir. Böylece doğanm bahşettiklerine ustalı̆̆n yararlar eklenir: Isste sanatın genel anlamı, önemi burada yatar". O halde -bilhassa geleneksel toplumlar için- müzik; maddi dünyanın, yani tabiatın, tekniğin, tarihin ve toplumun olanakları ile tabiatüstü bir tasavvuru mezceden bir ustalık ürünüdür. Bu bakımdan modernlik öncesi toplumlarda müzik; hem son derece öznel, soyut ve manevi bir kaynağa atıf yapmakta hem de somut gündelik yaşamın bütün alanlarına sirayet ederek ait olduğu toplumun geleneksel kodlarını taşıyıp sürdüren bir kültürel bellek işlevi görmektedir.

Ancak modernleşme tecrübesinin insanlığın inşa ettiği bütün geleneksel sistemler üzerinde yarattığ1 y1kıc1 tesir sanatlarda da kendini göstermiştir ki bilhassa 19. yüzyıl sonundan itibaren iyiden iyiye belirginlik kazanan bu dönüşümün izlerini müzik üzerinden takip etmek son derece açıklayıcıdır. Modernizmin en büyük çıktısı olan küresel kapitalizm, esas itibariyle sermayenin ve üretimin tarihindeki dönüşümü ifade etmekle birlikte insanlığın bütün bilgi, inanç ve estetik sistemlerini geleneksel bağlarından kopararak rasyonalize etmiş; bu arada her türlü sanatsal yaratım sürecini de yeniden-üretim ve tüketim bağlamında örgütleyerek sanat eserinin metalaşmasını kaçınılmaz hale getirmiştir. En kadim sanatlardan biri olan müzik, son derece derin ve yaygın bir toplumsal karşıllğı bulunması dolayısıyla bu süreçten dramatik bir biçimde etkilenmiştir. Artık müzikal yaratımın nihai neticesi bir eser değil, üründür; toplumun müşterek anlam dünyasından beslenen ve onu besleyen rafine bir sanatsal form değil, pazardaki değişim değerine göre kıymetlendirilen bir emtiadır. Müziğin alınıp satılması için öncelikle üretim sürecini standardize etmek ve ortaya çıkan ürünü vasatlaştırarak popülarize hale getirmek gerekir. Bütün bu süreç, modern kapitalist toplumlarda toplumsal ilişkileri tüketim ekseninde düzenleyen kurumlar aracıllı̆ıyla sistematize edilir. Kendi kültürel aidiyetinin rengini yitiren, toplumlanın organik nitelikleri ve ihtiyaçlanı ile bağlanını koparan müzik, bundan böyle yalnızca sahte ihtiyaçlar dayatan ya da "yanlış bilinç" üreten kültür piyasasının en önemli enstrümanı haline gelmiş ve aslinda fiili toplumsal durumun tüketicisinden saklandığı bir alan olarak değerlendirilmiştir (Oskay, 2001, s. 55).

Kültür piyasasının bir çıktısı olarak müzik -başka bir ifade ile popüler müzik- ekonomik ve ideolojik temerküzü mümkün kılan kültürel tahakkümün kalelerinden biridir ve bu alandaki değerlendirmeler bizi ister istemez "kültür" sahası ile ilgili tartş̧maların içine çekmektedir. Bu sahadaki hararetli tartışmalar, özellikle "popüler kültür” başlığı alında son derece kıymetli bir literatürün birikmesine imkân vermiştir. Popüler kültür ürünleri ve bu ürünler içerisinde en kolay alınıp satılabilen kalemi oluşturması dolayısıyla popüler müzik; Adorno’ya göre (1939 Aktaran Erdoğan \& Alemdar, 1994, s. 201), insanlarda içinde bulundukları durumdan uzaklaştıkları yanılsamasını yaratan, onları negatif etkilerden arındırarak pasifıze eden ve böylece onların kitlesel uyumunu kolaylaştıran bir araçtır.

Popüler kültüre yönelik bu negatif yaklaşımlar, bilhassa Frankfurt Okulu etrafinda kümelenen neoMarksist gelenekten beslenmektedir. Bu gelenek "Eleştirel Kuram" ya da "kültür endüstrisi" kavramsallaştırmasıyla modern kapitalist toplum eleştirilerinin en sert örneğini ortaya koymakta ve bu eleştirilerin önemli bir kısmı, popüler müzik bahsindeki değerlendirmeleri içermektedir. Fakat aynı gelenekten kopan ve özellikle İngiliz Kültürel Çalışmalar ekolü etrafında kümelenen bir başka yaklaşım, popüler kültürün kültürel iktidar ve hâkim sınıfların ideolojisi tarafindan belirlenen edilgenleştirici karakterini reddetmemekle birlikte onun halka dönük doğasına da dikkat çeker. Popüler kültürde özgürleştirici bir imkânın izini süren yeni yaklaşımlar, onun bu halka dönük karakterinde içkin olarak bulunan sisteme direniş imkânını işaret eder ve yukarıdan aşağı yönlü bir dayatmanın ürünü olmayan, halkın organik ihtiyaç ve özlemlerinden neşet eden pek çok popüler kültür ürünün varlığına önem verir. 
Bu nitelikteki bir kültürel üretim örneği olarak görebileceğimiz arabesk müzik olgusu, aşağıdan yukarı yönlü seyreden bir direniş potansiyeli barındırması ve temsil ettiği kitlenin organik nitelikleri ile belirli bir uyum gösteren karakteri dolayısıyla bütün bu kuramsal tartısmaların Türkiye özelindeki izdüşümünü takip etmek için elverişli örnektir. Ancak Türkiye'de popüler kültür alanı ile ilgili çalışmalarda önemli bir yer tutan arabesk müzik özelinde bir değerlendirme yapabilmek için, Cumhuriyet dönemi modernleşme tecrübesinde müziğin bir modernleşme aracı olarak değerlendirildiğini hatırlamak gerekir. Bu manada Türk modernleşme hedefleri doğrultusunda ideolojik bir araç olarak dizayn edilmek istenilen Türk müziği, Türkiye'nin modernleşme pratiğinin hem sonucu hem de bu pratiğe kültürel bir tepki olarak kendi içinden arabesk denilen bir alt tür çıkarmıştır.

Arabesk olgusu ile ilgili çalışmalar, Türkiye'de popüler kültür sahasına ilişkin literatüre önemli katkılar sunma potansiyeline sahiptir. Arabeski ve onun bir alt kültür ögesi olarak başlayıp gittikçe popüler hatta hegemonik bir kültürel biçime bürünen dönüşümünü anlamak, Türk modernleşmesine dair kavrayışımıza da büyük katkılar sunacaktır. Dolayısıyla bu çalışmada, Türkiye'nin kendine has modernleşme serüveninin çeşitli kültürel tezahürlerinden biri olan "arabesk" olgusu, popüler kültür bağlamındaki literatürden istifade edilerek ele alınmaktadır. 1960'larla başlayan arabesk furyasının dönemsel dönüşümlerine değinilmekte; arabesk müziğin periferiden merkeze doğru seyreden yolculuğu sırasında, sahip olduğu organik niteliklerden ve taşıdığı muhalif anlamlardan soyunarak tamamladığı öyküsü üzerinde durulmaktadır.

\section{Popüler Kültür Kavramı}

Kültür kelimesinin kökeni; toprağın ekilip biçilmesi, mayalanması, işlenmesi ve tarımsal bir ürün yetiştirilmesi gibi anlamlar içeren "colere" kelimesine dayanmaktadır (Erdoğan, 2008, s. 135). Latince kökenli "colere" filinden türetilen "cultura" kelimesi de Cicero'ya kadar aynı anlamı karşılayacak şekilde kullanılmıştır. Cicero "cultura" kelimesinin anlamını dönüştürerek "cultura animi”" şeklinde genişletmiş ve bundan sonra sözcük, insan nefsinin terbiye sürecini karşılayacak bir anlam kazanmışır (Özlem, 2005, s. 154). Giderek "kültür" kelimesi çok çeşitli unsurlanı kapsayan, karmaşık ve yaygın bir anlamsal çeşitliliğe ulaşmışır.

Kültür kavramı, bugün sosyal bilimlerin anahtar kavramlarından biri olmasına rağmen, farklı disiplinleri temsil eden isimlerin kavrama farklı kıstaslarla yaklaşmaları, kültüre dair müşterek bir tanım ortaya koyabilme imkânını kısıtlamıştır. Ancak kültür kavramı üzerinde müşterek bir tanım geliştirilememiş olması ve kavrama yönelik farklı yaklaşımların bolluğu, bu sahadaki çalışmaları zenginleştiren bir etki yaratmıştır. Çok çeşitli ögelerin bileşiminden meydana gelen ve geniş bir sahaya yayılan çalışmalar, özellikle sanayileşme ve küreselleşme gibi gelişmelerin bu sahadaki dinamikleri hızlı bir şekilde etkilemesiyle büyük bir ivme kazanmıştır. Giderek bu çalışmalara kültür kavramının çeşitli bölümlemelere tabi tutularak incelenmesi eğilimi hâkim olmaya başlamış; bu bölümleme eğiliminin önemli bir sonucu olarak kültürün popülarizasyon süreçleri ile ilişkisi üzerinden okunması, popüler kültür incelemelerini öne çıkarmıştır. Popüler kültür kavramına yönelik incelemeler 18. yüzyllla birlikte ivme kazanmış olsa da (Özbek, 1991, s. 77) popüler kültür kavramının ve kavram üzerindeki ihtilafın çok daha uzun bir geçmişten beslendiği görülmektedir. Uzun tarihi boyunca popüler kültür kavramını açılamaya yönelik farklı yaklaşımlar ortaya çıkmış, farklı tanımlamalar geliştirilmiştir.

Özbek'e (1991, s. 83) göre "popüler” kelimesinin günümüzde kullanıldığ1 biçimiyle iki tanımı bulunmaktadır. Hâkim olan birinci tanıma göre popüler, "yaygen olarak beğenilen ve tüketilen" anlamı taşımaktadır. Stuart Hall, bu tanımı popüler kültürün "ticari” tanımı olarak nitelendirmektedir. İkinci tanım ise kaynağı Herder'e dayanan ve "balka ait" anlamına gelen tanımdır ki Stuart Hall, halkın yaptığ1 ve yapmıs olduğu her şeyi kapsamaya çalışı̆̆ı için bu tanımı "betimleyici" tanım olarak adlandırmıstır (Aktaran Özbek, 1991, s. 83-84). Hall'un ticari ve betimsel olarak adlandırdığ1 bu iki tanım, kavram üzerindeki kutuplaşmanın temelini işaret etmekte ve popüler kültür incelemelerinin odak noktasını oluşturmaktadır.

Asında popüler kültür ile ilgili süregelen ihtilafin tarihi çok daha eski bir tartşmaya, Montaigne ve ona neredeyse bir asır sonra karşıllık verecek olan Pascal arasındaki ihtilafa kadar uzanmaktadır. Montaigne, birey üzerindeki baskıların tahribatı ve yalnızlığın dehşetini azaltmak için "sanat aracllğ̆ ile oyalanma ve eğlence"yi bir kaçış imkânı olarak önerirken Pascal eğlencenin yıkıcı ve ruhu çürüten etkisine karşı insanları uyarmaktadır. Montaigne ve Pascal arasındaki ayrışmanın temeli, onların boş zaman ve eğlenceye yönelik tutumlarındaki farklılığa dayanır. Montaigne’e göre boş zaman ve eğlence, insanlar için hayatta kalmayı 
güvence altına alırken Pascal'a göre tahrip edicidir (Löwenthal, 2017, s. 30-31). Bu iki temel ayrım günümüzde de boş zaman ve eğlence temaları etrafında şekillenen popüler kültüre ilişkin tartışmalarda etkisini hissettirmektedir.

Birkaç asır boyunca alana hâkim olan bu tartışma ve ihtilaflar, popüler kültüre yönelik değerlendirmeleri en temelde iki grup altına ele almayı gerektirmektedir: Popüler kültürü tamamıyla reddeden, onu anarşi ya da yozlaşmanın bir göstergesi olarak kabul eden olumsuz yaklaşımlar ve popüler kültürde egemen sınıfların kültürel iktidarına direnme imkânının izlerini arayan olumlu yaklaşımlar (Yllmaz, 2017, s. 512). Popüler kültürü reddeden olumsuz yaklaşımlar, muhafazakâr-seçkinci ekol ve neo-Marksist kitle kültürü eleştirisi tarafindan temsil edilirken; popüler kültüre olumlu bir özellik atfeden yaklaşımlar, büyük ölçüde Gramsci'nin "hegemonya" kavramsallaştırmasından beslenen İngiliz Kültürel Çalışmalar geleneğine dayanmaktadir.

Muhafazakâr-elitist ekol ve neo-Marksist yaklaşımın -özellikle Frankfurt Okulu etrafinda kümelenentemsilcileri, birbirinin tam aksi saiklerle ve paradoksal bir biçimde, popüler kültürle ilgili müşterek bir tavır takınmışlardır. Muhafazakâr-elitistler, popüler kültürü hâkim düzene ve kendi yerleşik imtiyazlarının teminatı olan sınıflı topluma yönelik bir tehdit oluşturmakla suçlarken; neo-Marksist yaklaşımın temsilcileri, tam aksi bir şekilde, popüler kültürü yerleşik düzenin lehine kitleleri eblehleştiren endüstriyel bir araç olarak mahkûm etmişlerdir. Bununla birlikte her iki ekol de popüler kültür kavramı yerine ekseriyetle "kitle kültürü" kavramını kullanmayı yeğlemiş ve eleştirilerini yüksek kültür ile kitle kültürü mukayesesi üzerinden yapmışır.

Elitist/seçkinci yaklaşıma göre, toplumsal yapı insanları iki sınıfa ayırmaktadır: Elitler ve vasıfsızlar. Elitler; vasıflı, yaratıcı ve seçici azınlıklardır. Bunların karşısında ise vasıfsız, entelektüel olmayan, kaba ve sürü halindeki kitle yer almaktadır (Yaylagül, 2016, s. 21). Ortega Y. Gasset 1930'da yayınlanan Kitlelerin Başkaldırısı kitabında egemen sınıfların endişelerini dile getirmektedir. Gasset’a göre "seçkinsiz bir toplum asla düsünülemez ve kitle gü̈ü ceteciliktir". Eliot ise Kültürün Tanmmlanması Üzerine Notlar adlı kitabinda "kültür standartlarmm gittikese geriledig̈̈ni ve bir zaman sonra hiçbir këlttürün kalmayacağgn" savunmuștur. Tutucu okulun mensupları popüler kültürü “yoz, bayağı ve alt tabakaya has bir eğlence biçimi” olarak niteleyip reddetmişlerdir. Örneğin Ernest Van den Hagg, "yülksek kültürü, kalitesini yok edecek kadar sulandermadan aşă̆ simflara uzatmanın mümkün olup olmadyğnı" sorarken aslında bu durumun imkânsızlğıını ima etmektedir. Hagg’a göre

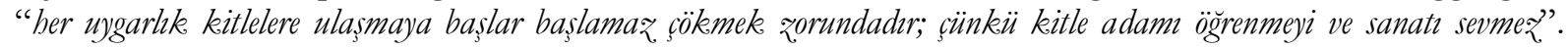
(Alemdar \& Erdoğan, 1994, s. 113-115). Le Bon, 19 yüzyllın sonlannda yazdı̆̆1 Kitleler Psikolojisi adlı eserinde kitlelere karşı duyduğu korku ve endişeden bahsetmekte, kitleleşme ile birlikte fertlerin bilinçli etkinliklerinin yerini kitlelerin bilinçsiz etkinliklerinin aldığından yakınmaktadır (Yaylagül, 2016, s. 89). Klasik ve muhafazakâr yaklaşımcılar açısından ele alındığında ise kültür, sadece estetik mükemmelliğin ölçütü olarak açıklanmaktadır. Arnold'un deyişiyle kültür, "dünyada düşünülen ve söylenenlerin en iyisini" temsil etmektedir (Aktaran Özbek, 1991, s. 78). Sanayileşmenin hızla yayılmasının kültürü boğma ihtimali üzerine derinden endişelendirmekte olan Arnold, kültürü " zihnin ve rubun içsel bir kossulu olarak mükemmellike ideasi" olarak tanımlamaktadır (Löwenthal, 2017, s. 63).

Popüler kültüre yönelik olumsuz yaklaşımların bir diğer sözcüsü; kitle toplumu anlayışı ve kültür endüstrisi kavramsallaştırması ile beslenen Frankfurt Okulu üyelerinin temsil ettiğgi neo-Marksist gelenektir. Eleştirel Kuram olarak da ifade edilen bu yaklaşım, kendi içinde bütünlüklü ve homojen bir yapı göstermekten uzak olsa da bir sosyalizasyon arac1 ve endüstriye dönüşerek statükonun ve sömürünün devamını sağlayan kültürün yeniden üretimi üzerine yürütülen çalışmaların temel teorik zeminini teşkil etmektedir. Bu geleneğin en önde gelen temsilcilerinden biri, farklı disiplinler üzerindeki ilgi ve uzmanlı̆̆ ile temayüz etmiş olan Theodor W. Adorno'dur. Adorno'ya göre (1998, s. 45) çoktan endüstrileşmiş bir meta haline gelen kültür, "insana yaraşan bir toplumda yaşandı̆̆ yanllsamasm yaratmakta, bütün insan ürünlerinin temelinde yatan maddi koşullar gözlerden saklamakta ve rahatlatip uyusturarak, varoluşun kötü ekonomik belirleniminin sürüp gitmesine birmet etmektedir".

İlk kez, Horkheimer'la birlikte 1947'de yazdıklan Aydınlanmanın Diyalektiüg isimli makalede dile getirmiş oldukları "kültür endüstrisi" kavramsallaştırması ile "metalaşma", "standartlaşma", "fetişleşme", "sahte bireysellik", "yabancılaşma" gibi temalar üzerinden endüstriyel toplum eleştirilerinin en sert örneğini sunmuşlardır. Kültür endüstrisi; her şeye benzerlik bulaştıran, kitlelere sahte ihtiyaçlar, sözde tercihler ve 
yanlış bilinçlilik sunan, böylece bağımsız yargılara ulaşma imkânını ellerinden alarak onları pasifize eden yapısıyla kapitalist toplumlarda kültürün yegâne üreticisidir. Adorno ve Horkheimer'a göre, kültür endüstrisinin standardizasyonundan geçen birey bir yanılsama haline gelmiştir. Frankfurt Okulu'na göre özgürleşme ve ütopik nitelik yalnızca yüksek sanatta mevcuttur (Özbek, 2011, s. 68). Oysa kitle toplumunda "sanat bir meta türüdür, yani tüketime uygun biçimde hą̧rlanmıss, (...) satılabilir ve ikame edilebilir" bir üründür (Horkheimer \& Adorno, 2010, s. 211).

Daha çok kitle kültürünü, yer yer de popüler kültürü ima eder şekilde kullandıkları kültür endüstrisi kavramıla Adorno ve Horkheimer, gösteri ve eğlence endüstrisinin gelişimiyle kitlesel olarak üretilen sanatsal ve kültürel ürünlerin metalaştığını ve bireylerin boş zamanının sisteme hizmet eden birer araca dönüştürüldügünü savunmaktadırlar. Bu bağlamda Adorno ve Horkheimer’a (2010, s. 185) göre "kültür

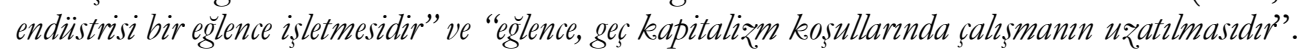

Bu noktada Löwenthal (2017, s. 83) tarafindan dile getirilen "popüler kültür üzerindeki ibtilaflarn taribsel arka planma, her tür eğlenceye yönelik Pascalcu bir kınamann egemen olduğg" yolundaki saptamalar önem kazanmaktadır. Popüler kültür alanı ile ilgili değerlendirmelerin istikrarlı bir biçimde popüler kültürü eğlenceyle bir tuttuğunu ve bu değerlendirmelerin genellikle olumsuz bir nitelik taşıdığını ifade eden Löwenthal'in kendisi de bu olumsuz yorumlara acımasız bir katkı sunmaktadır. Löwenthal'e (2017, s. 39) göre, "Popüler külttürün bir ürünü, bakiki sanatın özelliklerinden biçbirine sabip değildir ama bütün mecralaryla popüler kültürün kendine ait bakiki nitelikleri bulunmaktadr: standartlasma, basmakahp yargl, mubafazakârhk, yalanchlı, manipüle edilmis tüketim mallarn". Frankfurt Okulu geleneğinin önemli temsilcilerinden biri olan Löwenthal (2017, s. 31) için, "Popüler kültürün karşıt kavramı sanattır".

Fakat aynı geleneğin bir diğer temsilcisi W. Benjamin, popüler kültürün istikameti konusundaki tezleri ile bu gelenek içinde bir çatlak oluşturmaktadır. Tekniğin Olanaklaryla Yeniden Üretilebildiği Căgda Sanat Yapıtı isimli makalesinde Benjamin, sınır tanımaz çoğaltma sonucu yüksek sanat yapıtının sahip olduğu "kutsal hâle"nin (aura) kaybolduğunu; bunun da nihayet yüksek sanat ile popüler kültür arasındaki sınırları belirsizleştirerek yeni ve demokratik imkânlara işaret ettiğini vurgulamaktadır. Fred Inglis'a göre (Aktaran Mutlu, 2010, s. 224), "Kutsal bâle, mekanik soğaltma tarafindan kaybolmus olmakla birlikte, çoğaltılan sanatun bâleli sanata göre kö̈kten bir șekilde çok daha faそla demokratiklik olanağz vardır. Hâleli sanatun Benjamin'e göre kült değeri, diğerinin ise teşhir değeri bulunmaktadır".

Benjamin'in açtığ bu yol, popüler kültürü bir mücadele alanı olarak gören yaklaşımlar için ilham kaynağ1 olmuştur. Fakat büyük ölçüde "İngiliz Kültürel Çalışmalar" ekolü tarafindan temsil edilen bu yaklaşımın en önemli esin kaynağı, Gramsci ve onun literatüre kazandırdığı "Hegemonya Kuramı"dır. Gramsci'nin hegemonya kavramı, özellikle kapitalist toplumlarda hakimiyetin ne şekilde sürdürüldügünü açıklamak için geliştirilmiştir. Kavram başlıca bir yönetici sınıflar fraksiyonlanı anlaşmasını, bağımlı sınıflar üstünde, güce başvurmaksızın kapsayıcı bir hakimiyet oluşturması sonucunu doğurmaktadır. Ancak sözü edilen bu hakimiyetin en temel dayanağı ise bağımlı sınıfların "rıza"sı üzerinden sağlanmaktadır (Özbek, 1991, s. 81). Fakat "rıza" hiçbir toplum için verili ve sürekli değildir, bu sebeple rızanın yeniden üretilmesi biteviye bir mücadeleyi gerektirmektedir. Buradan yola çıkılarak popüler kültür, "karşıt baskıllar ve eğgilimler tarafindan biçimlenen güç alan ilişskileri” olarak görülmektedir (Alemdar \& Erdoğan, 1994, s. 104).

Kültürel Çalışmalar ekolünün önde gelen temsilcilerinden Stuart Hall, popüler kültür kavramını -alana hâkim olan olumlu ve olumsuz tanımları sentezleyerek- yeniden tanımlamaktadır. Özbek'e göre Hall, ticari olarak adlandırdığı ve "yaygun olarak kullanılan ve begenenilen" şeklindeki tanımlama ile betimleyici olarak adlandırdığı ve kaynağı Herder'e kadar uzanan “balka ait, halkın yaptı̆ her sey” sseklindeki tanımlama arasında bir köprü kurmaktadır. Hall, popüler kültür tanımında gerekli olanın popüler kültürü hâkim kültüre karşı sürekli bir gerilim içinde tanımlayan ilişkiler olduğunda ısrar etmektedir. Bu bağlamda popüler kültür, "Ilktidarda olanlarn kültürüne karşı ya da onun adina mücadelenin alanlarndan biridir. O mücadele içinde kazanulacak ya da kaybedilecek olan seydir" (Özbek, 1991, s. 89-90).

Kültürel Çalışmalar Ekolü, popüler kültürü halka ait bir alan olarak kabul etse de popüler kültürün yapısındaki ideolojik ve hegemonik unsurların varlığını reddetmemektedir. Kültürel Çalışmalar geleneği, popüler kültürün bir yandan kültürel iktidar ve hâkim sınıfların ideolojisi tarafindan belirlenen edilgenleştirici karakterine vurgu yaparken diğer yandan onun halka dönük doğasında içkin olan sisteme direniş imkânını işaret etmektedir. Burada özellikle popüler kültüre ait ürünlerin tüketilmesi anında halkın 
bilinçli tercihlerde bulunabilme kapasitelerinin altı çizilmektedir. Modleski (1998, s. 10), "Birmingham

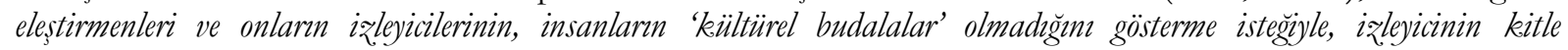
kültürüne karşı potansiyel tepkisinin karmaşıkhğın göstermeye" çalıştklarına değinmektedir. Stuart Hall, bu tepkinin alabileceği üç biçimi tartısmıştır: Metnin mesajlarını olduğu gibi kabul eden yaygın okuma, sistemin bütününü kabul ederken bir iddiayı tartışabilen ůlassmaya dayah tepki, alt sınıfların çıkarı için sistemi reddeden mubalif tepki. Buna göre, herhangi bir mesajın alımlanmasında bireylerin siyasal tercihlerinin ya da toplumsal tecrübelerinin etkisi, mesajı içeren metnin veya onu taşıyan kitle iletişim aracının etkisini bastırmaktadır. Böylece Hall; kitle kültürü kavramının ima ettiği atomize olmuş bireylerden oluşan, güdülmeye ve kolayca manipüle edilmeye teşne edilgen kitleler anlayışını reddetmekte ve tüketicileri aktif birer özne olarak yeniden tanımlamaktadır.

Kültürel Çalışmalar geleneğinin açtı̆̆ yol, toplumların gündelik yaşam kültürünün aslında ideolojik ögeler içeren bir sureti olarak popüler kültürü, aynı anda hem tahakkümün hem de direnişin rutin bir şekilde hüküm sürdügü bir mücadele alanı olarak bambaşka bir zaviyeden görmeyi mümkün kılmıştr. Bu geleneğin yarattı̆̆ kırılma, halkın gündelik yaşam kültürünü belirleyen ve aynı zamanda onun tarafindan belirlenen popüler kültüre dair pek çok ampirik çalışmaya da ilham kaynağı olmuştur. Steven Connor'in (2001, s. 270) ifadesiyle,

\begin{abstract}
'Richard Hoggart, Raymond Williams, Roland Barthes ve Stuart Hall'un esin verici önderlig̈ini iə̨leyen çağdas kültür eleștirmenleri konularm spor, moda, saç stilleri, alısveris, oyun ve toplumsal ritüellerden almaya başladilar ve herbangi bir yükesek kë̈ltür ürününden esirgemeyecekleri teorik incelik derecesini bu alanlara tașimaktan cekinmediler. Bir anlamda bu durumun kendisi bile postmodern bir fenomendir, zira ... kültürel, toplumsal ve ekonomik olann artık birbirinden kolayca aynt edilemediğ kültür alanindaki patlamamn bir sonucu olarak hiyerarşilerin törpülenmesinin ve sinirlarm bulanklasmasmm işaretidir".
\end{abstract}

Sınırların bulanıklaşması; bayağı, zevksiz ve aşağı tabakaya has görülen kültürel biçimleri ya da yoz, yabancılaşmış ve yanlış bilinçlilik telkin etmekle suçlanan popüler ürünleri görmezden gelen dışlayıcı yaklaşımların hâkimiyetini sarsmışııı. Böylece hâkim sınıfların hegemonyasının hem güvence altına alındığı hem de tehdit edildiği bir mücadele alanı olarak yeniden tanımlanan popüler kültürün çelişik ve belirsizliklerle örülü yapısı, sosyo-kültürel araştırmalar için değerli bir malzemeye dönüşmüştür. Popüler kültürün bu paradoksal yapısını açıklayabilecek önemli bir örnek olarak "Arabesk Kültür" olgusu da bu bağlamda mümbit bir inceleme sahası olarak dikkat çekmekte; arabesk ve onun çevreden merkeze yolculuğu üzerine yapılan incelemeler, Türkiye'de popüler kültürü anlamaya yönelik sosyal-bilimsel çalışmalar için önemli bir odak oluşturmaktadır.

\title{
3. Türkiye'nin Modernleşme Süreci Çerçevesinde “Arabesk”in Doğuşu
}

Modernliğin Sonuçları isimli eserinde Anthony Giddens gelenek üzerine yorum yaparken geleneği "bütünüyle durağan değildir, külttürel mirasm kendinden önce gelenlerden devralan her yeni kusak tarafindan yeniden ical" şeklinde açıklamakta ve bu yüzden geleneklerin değişime çok fazla direnç göstermediklerini vurgulamaktadır (Giddens, 1998, s. 42). Aynı eserde ise modernliğin yeni yaşam tarzlarını ortaya çıkardığını ve bu yaşam şekillerinin geleneksel toplum düzenden tarihte hiç rastlanmadık bir şekilde çekip ayırdığını, ayrıca geleneksellikle de modernlik arasında bir süreklilik doğurduğunu söylemektedir (Giddens, 1998, s. 14).

Modernleşme ile gelenek arasındaki bu gerilimli birlikteliğin ve Türkiye'nin kendine has modernleşme serencamının çeşitli kültürel tezahürlerinden biri de bir alt kültür ögesi olarak filizlenmeye başlamış olmasına rağmen giderek kitleselleşen ve baskın bir popüler kültür ögesine evrilen "arabesk" olgusudur. Her türlü popüler kültür ürünü gibi arabesk de modernliğin yarattığı gerilimin sonucudur; zira Özbudun'un (2010, s. 69) ifade ettiği gibi popüler kültür, modern yaşamın bir sonucu olarak karşımıza çıkmaktadır.

"Modernleşme" kavramı toplumsal, ekonomik ve siyasi süreçlerin karmaşık bir bütününe işaret etmektedir. Berman, bu karmaş1k süreci: "Sürekli ekonomik gelisme, endüstriyel yayılma, kentsel büyüme, 
bürokratik yönetim ve rasyonalite, kitle iletişim araçlar, siyasette kitle katullmı, büyük sürekli toplumsal planlama, geleneksel kültür ve hayat biçiminin parçalanması, üretkenlig̈̈n artturlması ve gelisme konusunda sürekli bir ısrar..." şeklinde tarif etmiştir (1978 Aktaran Özbek, 1991, s. 55). Elbette hâkimiyetini kapitalist iktisadi süreçlerin gelişimine borçlu olan modernleşme tecrübesi, farklı coğrafyalarda farklı biçimlerde tezahür etmektedir. Türkiye'de modernleşme serüveninin kültürel alandaki en "popüler" tezahürü, 1960’lar itibariyle varllk göstermeye başlayan "arabesk" fenomenidir. Türkiye'nin modernleşme yolculuğunun en çetin safhalarına şahitlik eden 1950’ler dönemi, sanayileşmenin ve buna bağlı olarak kentleşmenin yakaladığı ivme ile çok keskin dönüşümlere sahne olmuş; yaşanan değişimin ortaya çıardığı göç, gecekondulaşma ve çarpık kentleşme gibi komplikasyonların, arabeskin vücut bulmasını sağlayan sosyolojik zemini oluşturduğu kabul edilmiştir. Ancak arabeskin doğuşunu ve bu toprakların kültürel vasatı üzerinde bu derece tayin edici bir rol oynamasını mümkün kılan etmenlerin, bir yönüyle, cumhuriyetin ilk yıllarının modernleşme politikası ile bağlantılı olduğunu söylemek mümkündür.

Son derece çetin koşullarda kurulan Türkiye Cumhuriyeti, bilhassa tek parti dönemi boyunca, yukarıdan aşağı yönlü, otoriter ve monist karakterli bir modernleşme politikası benimsemiştir. Findley’e göre (2017, s. 247), cumhuriyet elitlerinin benimsediği seçkinci halkçıllk, Türk halkını kendi modernlik tahayyülleri doğrultusunda zorla yükseltme ve ileri götürme kararlılığını göstermiştir. Kültürel modernleşme projesinin bir adımı olarak uygulamaya konulan "resmi müzik politikası", bu kararlılığın tezahürlerinden biri olarak görülmektedir. Çağdaş ve ulusal bir Türk müziği oluşturma gayesine matuf çabalar, müziğin cumhuriyetin politik hedefleri doğrultusunda ideolojik bir araç olarak dizaynını mümkün kılmıştır. Bu minvalde öncelikle Türk müziği eğitimi yasaklanmış, ardından 1934 yllında başlayan ve iki yıl sürecek olan Türk müziğine radyo yayın yasağının uygulanması ile halk kendi öz müziğini radyolarından dinleyememiş̧tir (Aktaran Güngör, 1993, s. 66). "Geri” ve "arkaik" olarak kodlanan Türk müziği halkın gündelik hayatından çıarılmış, bunun yerine halka modern Batı müziğinin benimsetilmesi amaçlanmıştır.

Özbek (1991, s. 146), 1930’ların ortasında yaklaşık 20 ay gibi bir süre için Türk müziğinin radyoda yasaklanarak, yayınlanmamıştır. Ayrıca Klasik Türk Müziği eğitimine de aynı süreçte bir yasak gelince akla "yeni Türkiye Cumburiyetinin Osmanlyyla kültürel bağlarm topyekûn koparma" isteğinde olduğu ve demokrasi anlayışında "halka rağmen" niteliğinin de bir göstergesi olarak kabul edildiği varsayılmaktadır. Müzik eğitimi veren okullarda gelenekselin reddi öyle boyutlara ulaşmışır ki öğrenciler sahip oldukları Batı sazlarıly kazara bile bir Türk müziği ezgisi çalsalar, okul yöneticileri tarafindan disiplin cezasina çarptırlabilmektedirler (Güngör, 1993, s. 65-66). Fakat uygulanan bu yasaklarla birlikte halk Arap radyolarına ve buradaki müzikleri dinlemeye yönelmiştir (Özbek, 1991, s. 146). Türk musikisinin makamsal melodilerine alışkın olan halk, kendi musikisine Batı müziğinden yakın bulduğu ve birtakım tanıdık tınılar içerdiği için Arap müziğine yönelmiştir. Arap radyolarının ve ardından bir furya halini alan şarkılı Mısır filmlerinin etkisi ile Arap müziğinin Türkiye'de yayılmaya başladığı görülmüştür. Türk müziğinin eğitimi ve yayılmasının önündeki engeller kaldırıldıktan sonra bile içli ve kırılgan Arap nağmelerinin halk nezdindeki popülerliği devam etmiştir (Aktaran Güngör, 1993, s. 68-69). Başta Saadettin Kaynak olmak üzere pek çok müzisyenin Mısır filmlerinin müziklerine yaptıkları Türkçe uyarlamalar ile ortaya çıan icra biçimi, klasik Türk müziğini tanınmaz hale getirmiş ve 1950 'ler döneminin müzikal olarak da bir geçiş dönemi olarak değerlendirilmesine sebep olmuştur. Tüm bu gelişmeler, 1960'lar itibariyle endüstriyel modernleşme süreçlerinin hızla dönüştürdüğü sosyolojik yapının yeni bir kültürel tezahürü olarak kabul edilen arabesk müzik türünün ortaya çıkışını ve yaygınlaşmasını kolaylaştırmıştır.

Özbek (1991, s. 145), 1960'lara kadar "arabeski ortaya çlkaran etmenlerin hem müzilksel hem de toplumsal olarak, kendilig̈inden ve müdahaleci yönleriyle, 'modernlessme' pratiğinin kendisine” bağımlı olduğunu belirtmektedir. $\mathrm{Bu}$ modernleşme pratiğinin en dikkat çekici tezahürleri, hızlı kentleşmenin yarattığı göç olgusu ile ortaya çıkmıştır. Güngör'ün paylaştı̆ı verilere göre 1950 ve 1960 yılları arasında başlıca dört büyük kentin nüfusunda yaklaşık yüzde 75 oranında bir artış yaşanmıştır. Yaşanan bu artışla birlikte kent nüfusunun toplam nüfus içindeki oranı yüzde $19^{\prime}$ dan yüzde 26 'ya kadar çıkmıştır. $\mathrm{Bu}, 1,5$ milyon göçmenin kentsel alanlara, bunların 600 bininin ise en büyük dört kente dağılmış olması demektir. Sözü edilen bu Bu mekânsal hareketlilik fiziki mesafeleri tamamen yok eden, merkezle çevrenin kültürünü karşı karşıya getiren ülke içindeki bütünleşmenin başlangıç noktası olarak görülmüştür (Güngör, 1993, s. 83). 
etmiştir (Şahin, 2014, s. 9). Ancak bu sınırlamalar arabeskin kitlesel bir hızla yayılmasını engelleyememiş; Güngör'ün de belirttiği gibi (1993, s. 81), TRT denetimini geçemeyen arabesk şarkılar için gazinolar, kenar mahalleler ve henüz boy gösteren gecekondu semtleri oldukça elverişli birer barınak olmuştur.

\section{Arabeskin Çevreden Merkeze Yolculuğu}

Bir yandan sergilediği yozlaşma ve yabancilaşma görüntüsü dolayısıyla eleştirilen arabesk müzik, diğer yandan halka ait, halkın kendi gerçekliğinden neşet eden organik bir ürün olarak görüldüğü için savunulmuş; dışlayıc1 ve yok sayıcı tutumların aksine arabeske ve onun dayandığ1 sosyal zemine, seslendirdiği mesaja, yarattı̆ğ dönüşüme kıymet veren yaklaşımlar da sergilenmiştir. Arabeskin yarattı̆̆1 anlam dünyasını olumlayan bu yaklaşımlar genellikle Kültürel Çalışmalar ekolünün açtığı yolu takip eden isimler tarafindan dillendirilmiştir. $\mathrm{Bu}$ anlamda Türkiye'de Kültürel Çalış̧alar geleneğinin öncü isimlerinden biri olan ve arabeski bir "yaşam biçimi" olarak gören Murat Belge'nin (1983, s. 264) oldukça erken bir dönemde isabetle kaydettiği şu tespitler dikkate şayandır:

\section{"Arabesk denilen 'yasam biçimi' Türkiye'nin sarsıc bir değ̊şsim geçirdiğ dönemde ortaya çıktı. Bir tarafta gerçek anlamda kurumlassmaya çalssan Batı değerleri, öbür tarafta yok olma durumuna gelmis geleneksel kültür. Bu durumda ne Batı kültürü kendini yeniden üretebilmektedir, ne de Doğg kültürü. Buna karşsllk Doğu ile Bati'nn eklektik karş̧ım olan arabesk, gelenekten kopmayan bir yenilik, Türkiye'de en yaygin yeniden üretimi olan kültür biçimidir".}

Arabeskin akademik alanda tabu olarak görüldüğü bir dönemde Kültürel Çalışmalar geleneğinin izini takip ederek hazırladığı doktora çalışması ile Meral Özbek, arabeski kent kültürünün bir parçası ilan ederek yerleşik kanaatlere radikal bir biçimde karşı çıkmıştır. Özbek'e göre arabesk müzik, 1960’larda kente göç eden kırsal nüfusun "çevreye uyumsuzluğunun" değil çevreye uymasının, var kalmanın yolunu bulabilmesinin başarlı bir göstergesidir. Diğer bir ifadeyle arabesk müzik şehir kültürünün ürünüdür: "Ortaya çıkışın sağlayan tüm etmenler sanayileşme süreci ile birlikte gelen ve ancak kentlerde varlk bulan etmenlerdir" (Özbek, 1991, s. 26-27).

Kültürel Çalışmalar geleneğinin popüler kültürü hem boyun eğmenin hem de direnmenin alanı olarak tarif eden yaklaşımı, arabesk kültüre olumlu bir misyon yükleyen görüşlere dayanak oluşturmuştur. Özbek (1991, s. 95) en azından 1968'den 1970'li yılların sonuna kadar arabeskin aşağıdan yukarı nitelikli bir kültürel hareket olma özelliğini, yukarıdan aşağı dayatllan bir kitle kültüründen farklı olduğunun kanıtı olarak göstermiştir. Stokes ise, gecekondu ve dolmuş müziği gibi tanımlamalara karşı çıarak arabeskin toplumun tüm katmanlar1 tarafindan kabul görmüş bir müzik olduğunu söylemektedir. Stokes'a göre arabesk, çevrenin merkeze tepkisi olarak ortaya çıkmış kentli bir müziktir (Aktaran Yılmaz, 2017, s. 518).

Ancak, egemen sinıflarca empoze edilen kültürel biçimlere muhalif olan ve halkın kendi gerçekliğinden doğan organik bir ürün olması sebebiyle arabeske olumlu bir anlam atfeden yaklaşımlar, onda başkaldırma imkânı kadar boyun eğmenin olanaklarının da içkin olduğunu kabul etmektedirler. Zira arabesk şarkı sözlerinde var olan isyan ve kadercilik ikileminin ifade ettiği çelişkiyi, bir popüler kültür ögesi olarak arabeskin taşıdığı direnme ve boyun eğme ikileminin varllğına dair bir gösterge olarak kabul etmek mümkündür. Bu anlamda Türkiye'nin modernleşme sürecine bir cevap olarak ortaya çıktığı kabul edilen arabesk olgusunun hâkim sınıfların hegemonik projesine eklemlenme potansiyelinin de üzerinde durulmuştur (Özbek, 1991, s. 95). Arabeskin ikinci dönemi olarak ifade edilen 1980 sonrası dönemde, onun gittikçe çevreden merkeze doğru seyreden yolculuğunun ve egemen söyleme uyum sağlama eğiliminin, bu eklemlenme potansiyelinin bir sonucu olduğunu söylemek mümkündür.

Arabeskin bir isyan müziğine dönüşemediğine değinen Stokes, bunun sebebini Türkiye'deki solun, devletin Batllıaşma hamlelerini benimsemesi ve bu nedenle de oryantal olan bu müziği dışlamalant ile açıklamaktadır (Aktaran Yılmaz, 2017, s. 518). Sol ve muhalif cenaha hâkim olan bu eğilime karşın dönemin iktidar kesiminin arabeske dair olumlu bir söylem geliştirdiği görülmektedir. Özellikle Turgut Özal'ın başbakan olmasıyla arabesk nağmelerin Başbakanlık konutundan Cumhurbaşkanlığ makam aracına kadar yayıldığı görülmüştür (Şahin, 2014, s. 7). Findley (2017, s. 336), arabeskin 1980’den sonra 
kazandığı bu itibarı, onun seçmenlerin gönlünü kazanmak için bir aksesuar olarak kullanılmış olması ile açıklamaktadır. TRT'deki resmi yasaklı konumu devam etmesine rağmen 1979 yılında Orhan Gencebay, iki yıl sonra yani 1981 yllında ise Kibariye TRT’nin ylbaşı gecesi için düzenlediği programda sahneye çıkmış ve böylelikle arabeskin yaygınlaşmasına olduğu kadar ifade ettiği muhalif anlamın çözünmesine de hizmet ettiğini söylemek mümkündür. 1980'lere gelindiğinde arabeskin yaygın olan türleri makbul sınırdan içeri alınmakta ve dönemin başbakanı Turgut Özal'ın da konuşmalarının satır aralarında kendisine yer bulmaktadır. Hatta Özal'ın 1988 yllında yaptığı bir konuşmada arabeskin TRT'de yayınlanmasında bir "mahzur" olmadığını beyan etmiştir. Öyle ki dönem içindeki devletin en önemli kültür kurumunu arabeske kapılarını açmıştır (Özbek, 1991, s. 139).

Özbek (1991, s. 124), 1980 sonrası arabeskin toplumsal anlamının değiştiğini ifade ederken gerek müzikal üretimi, müzik yapısı, şarkı sözleri ve tüketici profili gerekse toplumsal anlamı açısından arabeskte açıkça görülebilir olan bu değişimin; müzik endüstrisinin gelişmesi, kentlerdeki nüfus yoğunluğunun, niteliğinin ve zevklerinin değişmesi ve toplumsal-siyasal ortamın farklılaşması gibi birbirine eklenerek etkileşen faktörlerle yakın ilişkisi olduğunu belirtmektedir. Gürbilek (2001, s. 103) ise arabeskin bu dönem itibariyle değişen seyrini açıklarken bilhassa 80 'lerin ikinci yarısından sonra kendisini hissettiren "aşağ1 kültür patlamasına" vurgu yapmaktadır. Gürbilek, bu durumun "kültür endüstrisi" olarak ifade edilebilecek mekanizmaya eklemlenen kışkırtılmış bir yönü olsa da, esas vurgulanması gerekenin, 80’lere damgasını vuran patlamanın bu toplumun bugüne kadar inşa ettiği modern kimliğe yönelik doğrudan ve çıplak bir tepkiyi içermesi olduğuna işaret etmektedir. Bu anlamda Gürbilek (2001, s. 107) arabeskin yükselişini, "bastırılmış olanın geri dönüşü" olarak ifade etmekte ve şu hatırlatmay1 yapmaktadır: "Geri dönen biçbir

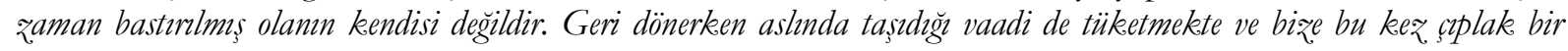
öfke, bir arsıそlık, bir açlk olarak görünmektedir".

1980'lerle birlikte gittikçe bir tüketim toplumuna doğru evrilen Türkiye'de arabesk, tüketim toplumunun alt kültürlere ait biçimleri kendi anlam ve içeriklerinden arındırarak piyasaya sürmesi şeklinde işleyen sürece uygun olarak dönüşüme uğramış ve muhalif anlamlarından soyunmuştur. Özbek (1991, s. 130) arabeskin ikinci dönemini açıklamak için, hâkim ideolojinin hakiki ihtiyaç ve özlemlere seslenerek onu kendi sistemi içinde emdiğini vurgulamaktadır. Bu dönem itibariyle arabesk müzik kendi içinde farklılaşan, kendinden türeyen alt kategorilere ayrılan baskın bir popüler kültür ögesine dönüşerek periferiden merkeze doğru her sınıftan insana ulaşmış ve hızlı bir yayılma göstermiştir. Artık türdeş bir müzikal niteliği ifade etmeyen arabesk müziğin bu döneminde, 1968'de çıkardığ1 ilk plağı Bir Teselli Ver ile arabeskin doğuşunu müjdeleyen ve bu sebeple arabeskin babası sayılan Orhan Gencebay, $70^{\prime} l e r$ boyunca arabesk piyasasının zirvesindeki konumunu yeni isimlerle paylaşmak zorunda kalmıştır. Sadece Orhan Gencebay'1 kendisinden sonra gelen yeni arabesk ikonları ile mukayese etmek bile, arabeskin ne tür bir dönüşüm geçirdiğini anlamamıza yarayacak ipuçları barındırmaktadır.

Murat Belge'nin "güvenli, dik ve vakur, naziik ve uygar" olarak tarif ettiği Orhan Gencebay; aydın kimliği ile popülerliğin, teknikle sokağın sesinin, düşünce ile isyanın buluşabildiği bir dünyada popüler olmuş ve adil olmayan babaya karşı ailenin haklarını korumaya çalışan bir "ağabey” payesine layık görülmüştür (Gürbilek, 2011, s. 96-97). Oysa 1980’lerin siyasi ve kültürel iklimi, Orhan Gencebay'in şahsında karşllğı̆nı bulan o nahif ve ağırbaşlı isyana değil, İbrahim Tatlıseslerin temsil ettiği ve Gürbilek’in (2001, s. 99) ifadesi ile "artı yabanc topraklarda kendine güvenmeyi ögrenmis, yabanc bir dili bozmayz, yabancilara kafa tutmay öğrenmis, yrrtık ve yartılmış bir ses"e denk düşen bir seyir izlemektedir. Bu dönemin yeni popüler kültür idolü olan Tatlıses ve türevleri, taşranın merkezle buluştuğu ve piyasa ile kışkırtıldığı anda sergiledikleri tavırlarla Orhan Gencebay'1 arabeskin seçkini konumuna hapsetmişler, onun hayranlarına belli bir mesafeden seslenen ölçülü tavrının aksine ölçüsüz bir yakınlıkla kitlelere dokunabilmişlerdir.

1990’lı yıllara gelindiğinde özel televizyon kanallarının açılması ile arabesk müzik kendisine yeni mecralar bulmuş; bilhassa özel televizyonların müzik kanallant, arabeskin her türüne ait nağmelerle dolup taşmaya başlamıştır. Dönemin iktidarının arabeske yeşil ışık yakan beyanlarının da etkisiyle TRT'de bir tutum değişikliğine gidilmiş; çeşitli arabesk parçaların "popüler müzik" başlığı altında sunumuna imkân sağlanmıştrr (Güngör, 1993, s. 102).

Arabesk, 90’lardan sonraki yolculuğu boyunca diğer müzikal tür ve biçimlerle sıkı bir etkileşim içine girerek onları etkilediği kadar onlardan da etkilenmiş ve daha çok "pop-arabesk" şeklinde tarif edilen bir 
biçime dönüşmüştür. Bir gecekondu ya da dolmuş müziği olarak periferiden başladı̆g yolculuğunu merkeze yerleşerek tamamlamış, fakat bu sırada özgün bir tür olarak doğduğu sıradaki tüm organik niteliklerinden arınarak piyasanın standardizasyonuna tabi endüstriyel bir meta haline dönüşmüştür. Gittikçe bir piyasa dayatması halini alan, kendine has modası ve yaşam felsefesi ile izler kitlesine ait her şeyin tarif ve standardize edildiği bir arabesk endüstrisinden bahsetmemiz mümkün hale gelmiştir.

Günümüze uzanan yolculuğu boyunca arabesk müzik bütün sınıfsal alt anlamlarından ve iddialarından soyunmuş, egemen söyleme yönelik bir direnişi ima eden çağrışımlarından arınmış ve bütün müzikal formlarla estetik ve teknik anlamda alışveriş halindeki bir türe evrilmiştir. Buna en iyi örnek, arabeskin en radikal ve "damardan" örneğini sunarak 90’lı yıllara damgasını vuran müziği ve "Müslümcüler" olarak adlandırılan fanatik hayran kitlesi ile bir fenomene dönüşmüş olan Müslüm Gürses'in 2000’li yıllarda sergilediği dönüşümdür.

2000'li ylllar, Küpçük'ün (2018) ifadeleriyle, “Türkiye'de siyaset ve sosyolojinin 1950'lerden itibaren sıkıştrmaya

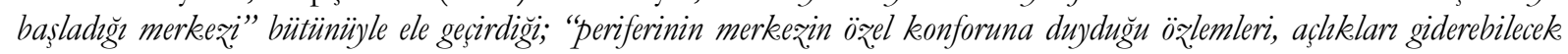

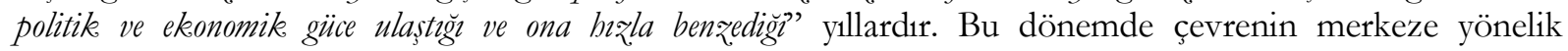
yürüyüşü nihayete erdiği ve arabeski besleyen çatışma durumu ortadan kalkttğ́ için üçüncü ve nihai bir döneme girildiği görülmektedir. Bu bağlamda Türk Pop müziğiyle aynı kefeye konulmayan ve genellikle de kentsoylu olarak tanımlanan Bülent Ortaçgil'in de bir şarkısının Müslüm Gürses tarafından icra edilmesinin aslında "merkęle geverenin en gösterişli buluşmasi" olarak açlklamaktadır. Gürses'in önyarg1ları alt üst eden sıçrayışı bununla kalmamış; fanatik "Müslümcü” kitleyi küstürmek pahasına Murathan Mungan'ın projesi çerçevesinde Garbage, David Bowie, Leonard Cohen, Bob Dylan ve Björk gibi Batılı müzisyenlerin şarkılarını Türkçe sözlerle yeniden seslendirmesi, müzikal türler arasındaki geçişkenliğin ispatı olduğu gibi arabeskin merkeze ulaşmasının da ilanı olmuştur. Artık arabesk feryadını terk etmiş, şarkısını tüketmiş, kendi öyküsünü tamamlamıştr.

\section{Sonuç}

Günümüzde arabesk; ideolojik, kültürel ya da sınıfsal aidiyetlerin hudutlarını aşan ve son derece yaygın olarak tüketilen kolektif bir kültürel biçimi ifade etmektedir. 1980’lerden sonra merkezin kültürel kodlarına eklemlenme temayülüne girmiş ve bugün kültürel olarak merkeze ulaşmış olsa da tüketicileri için hala "gündelik hayatın bir eleştirisi, onun dışına taşmak ve hayatın çerçevesini genişletmek için bir çağrı" (Özbek, 1991, s. 121) niteliği taşıyan anlamını korumaktadır. Fakat arabeskin tüketici kitlesi için son derece masum ve makul olan bu anlam, onu yozlaşmanın ve bozulmanın tezahürü olarak gören bir kesim için "hızla yitirilen bir şeyleri çağrıştırmakta" (Erol, 2011) ve arabesk hala "yoz ve bayağı" olarak değerlendirilmektedir. Eski merkezin elitlerine göre arabesk, yalnızca kültürel olarak değil, ekonomik ve siyasi olarak da merkeze ait iktidar alanlarına hükmetmektedir. Dolayısıyla bu kesim, toplumsal alandaki her türlü bayağılaşma için zaten yoz olarak nitelendirdikleri bu kültürü suçlamaktadır.

Böylece arabesk ekseninde farklılığını koruyan yaklaşımlar, kültürel kutuplaşmalarımızın önemli bir parçasını oluşturmaya devam etmektedir. Oysa Cem Behar'ın ifade ettiği gibi "Yoz müził yoktur, kötü mų̈̈ik yoktur... Tür olarak önceden, a priori olarak kötü diye niteleyebileceğimiz bir mürį türü yoktur. Olsa olsa kötü icralar, kötü yorumlar vardir" (Aktaran Özbek, 1991, s. 22). Müziği birtakım kategorilere zorlamak, müziğin kendi tabiatına aykırı olduğu gibi her alanda sınırların buharlaştı̆̆ günümüz dünyasında hepten nafile bir çaba olacaktır.

Aslında buharlaşan bu sınılların merkez ve çevre ayrımına dair tanımlarımızı muğlaklaştıran etkisini, arabesk müziğin ve bu müziği besleyen tabanın dönüşümü çerçevesinde düşünmek, yeniden üretilen toplumsal kategorileri anlamak için bize kıymetli bir açılım imkânı sunmaktadır. Bir alt kültür biçimi olarak ortaya çıktğı andaki organik niteliklerinden ve muhalif simgelerinden siyrilarak merkeze doğru ilerleyen arabesk, kendisini besleyen tabanda da karşıllı bulan bir dönüşüm sergilemiştir. Bu dönüşümü, merkez ile çevrenin yeni ve durmadan değişen sakinleri açısından hakkaniyetle okuyabilmek ise ideolojik kapanlara takılmadan ve genel geçer kabullerin kolaycllğıına sığınmadan, bu sahada incelikli bir akademik gayretin gösterilmesi ile mümkün olacaktır. 


\section{Extended Abstract}

Music, which has an important place in interpersonal communication, is not only a work that belongs to the person who composed and voiced it, but also has the characteristic of being a universal art by appealing to a group or audience in the society as a result of the common feelings, thoughts, joy and pain it contains. These feelings and thoughts, which enable the music masses to meet on a common ground, vary in relation to the economic, political and cultural structure of the period. In this respect, the birth and development of arabesque music has gained momentum with the economic-based depressions such as unemployment, increased slum life as a result of the lack of housing as a result of the migration that started from the village to the city in the 1950s, and the depression experienced at the point of adapting to the urban environment. As a music genre, what distinguishes arabesque from other music genres is its style and structure. The acceptance of this music genre, which is described as the expression of pain, has also taken place within difficult processes. Being ignored or postponed as the music of corruption and alienation after a long time its emerge as a cultural response to Turkey's modernization adventure, arabesque has been the object of official prohibitions and embargoes as well as elitist and exclusionary attitudes.However, the phenomenon of arabesque, which spread massively with the help of the social dynamics on which it rests, gradually joined the cultural codes of the city and it has evolved into a dominant popular culture item by breaking and reproducing these codes. It is possible to base the basic theoretical basis of the exclusionary approaches to Arabesk on the Conservative-elitist school and the Frankfurt School tradition. But elitist approaches that bring these two uncompromising traditions together in the anti-popular culture, it has given birth to an intellectual medium that makes it impossible to make healthy solutions regarding the arabesque phenomenon in Turkey. Some intellectuals, following the traces of the British Cultural Studies tradition in order to break this mediocrity, have carried the positive connotations of the tradition into the works they developed to understand and transform arabesque.In this study, 'arabesque' as the tense coexistence between tradition and modernity and as one of the Turkey's various cultural manifestations; various approaches are discussed around the theoretical differences mentioned. In the study, the transformations that started in the 1960s were mentioned, and the story that it completed with the organic qualities it had in its journey from the periphery to the center and the opposing meanings it carried were emphasized.

\section{Kaynakça}

Adorno, T. W. (1998). Minima Moralia. (Çev: Orhan Koçak, Ahmet Doğukan). İstanbul: Metis Yayınları.

Adorno, T. W., Horkheımer, M. (2010). Aydmlanmann Diyalektiği. (Çev: Nihat Ülner, Elif Öztarhan Karadoğan). İstanbul: Kabalc1 Yayınevi.

Belge, M. (1983). Cumhuriyet Döneminde Batllilaşma. Cumburiyet Dönemi Türkiye Ansiklopedisi içinde. İstanbul: İletişim Yayınlanı.

Connor, S. (2001). Postmodemist Kültür/Çağdaş Olanın Kuramlarna Bir Giriş. (Çev: Doğan Şahiner). İstanbul: Yap1 Kredi Yayınları.

Eğribel, Ertan (1984). Niçin Arabesk Değil? Ankara: Süreç Yayıncilık.

Erdoğan, İ. (2008). İletişimi Anlamak. Ankara: Ümit Yayıncillk Ltd. Şti.

Erdoğan, İ., Alemdar, K. (1994). Popüler Kültür ve İletişim. İstanbul: Ümit Yayıncilık.

Erol, N. (2011). Arabeskin Anlam Dünyası: Müslüm Gürses Örneği. http://www.academia.edu/574346/Arabeskin_anlam_dünyası_Müslüm_Gürses_örneği (Erişim Tarihi: 15.08.2020).

Findley, V. C. (2017). Modern Türkiye Taribi. (Çev: Güneş Ayas). İstanbul: Timaş Yayınları.

Giddens, A. (1998). Modernliğin Sonuçlarr. (Çev: Ersin Kuşdil) İstanbul: Ayrıntı Yayınları.

Güngör, N. (1993). Arabesk Sosyokültürel Açıdan Arabesk Mürik. Ankara: Bilgi Yayınevi.

Gürbilek, N. (2001). Vitrinde Yașamak. İstanbul: Metis Yayınları.

Karşıc1, G. (2010/1). Müzik Türlerine İdeolojik Yaklaşım: 1970-1990 Y1lları Arasındaki TRT Sansürü. Folklor/Edebiyat, (16/61), 169-178. 
Küpçük, S. (2018). Çevre'nin Merkez’e Meydan Okuyan Melankolik Sesi: Müslüm Gürses. www.dunyabizim.com: https://www.dunyabizim.com/muzik/cevrenin-merkeze-meydan-okuyanmelankolik-sesi-muslum-gurses-h31169.html adresinden alındı. (Erişim tarihi: 10.08.2020).

Löwenthal, L. (2017). Edebiyat, Popüler Kültür ve Toplum. (Çev: Beybin Kejanlıŏ̆lu) İstanbul: Metis Yayınları.

Modleski, T. (1998). Eğlence Incelemeleri. (Çev: Nurdan Gürbilek) İstanbul: MetisYayınları.

Mutlu, E. (2010). Kitle İletişim Kuramlar. Ankara: Ütopya Yayınevi.

Odabaşı, F. (2006). Dil-Kültür Bağlamında Müzik Dili ve Bunun Sosyal Bütünleşmedeki Yeri. Istanbul Üniversitesi İlabiyat Fakültesi Dergisi(14), 237-258.

Oskay, Ü. (2001). Müzik ve Yabancılaşma. İstanbul: Der Yayınlan.

Özbudun, S. (2010). Sinf, Kültür, Kimlik Yątlar. Ankara: Ütopya Yayınları.

Özbek, M. (1991). Popüler Kültür ve Orhan Gencebay Arabeski. İstanbul: İletişim Yayınlar1.

Özlem, D. (2005). Kültür Bilimleri ve Kültür Felsefesi. Ankara: DoğuBatı Yayınları.

Stravinsky, I. (2000). Altı Derste Mü̊iğin Poetikası. (Çev: C. Taylan). İstanbul: Pan Yayıncılık.

Şahin, C.. (2014). Türkiye'de Arabesk Müzik Kültürü ve TRT Sansür Kararlarının Etkisi: "Sen Benim İçimde Bir Korkulu Rüya..” http://www.umut.org.tr/userfiles/files/Document/document_3a6af37d21fe4153b28872d7b54f2982.pdf (Erişim Tarihi: 2. 08. 2020).

Yaylagül, L. (2016) Kitle Iletişim Kuramları. Ankara: Dipnot Yayınları.

Y1lmaz, Ö. (2017/8). Türkiye’ de Modernleşme, Popüler Kültür ve Arabesk. International Journal of Social Science (58), 511-522. 